\title{
Diferentes fontes de ferro na prevenção da anemia ferropriva e no desempenho de leitões lactentes
}

\author{
[Different sources of iron for the prevention of iron deficiency anemia and performance \\ of suckling piglets] \\ R.F. Almeida ${ }^{1}$, E.L. Lopes $^{2}$, R.C. Nunes ${ }^{2}$, M.P.C. Matos $^{2}$, L.M. Pascoal ${ }^{2}$, R.V.C Freire ${ }^{1}$, \\ M.C.S. Fioravanti ${ }^{2}$ \\ ${ }^{1}$ Universidade Federal de Goiás - UFG - Goiânia, GO \\ ${ }^{2}$ Escola de Veterinária e Zootecnia - Universidade Federal de Goiás - UFG - Goiânia, GO
}

\begin{abstract}
RESUMO
Com o objetivo de avaliar o uso de diferentes fontes de ferro na prevenção da anemia ferropriva e no desempenho em leitões lactentes, dividiram-se 202 leitões em cinco tratamentos: FD - aplicação intramuscular de $200 \mathrm{mg}$ de ferro dextrano no terceiro dia de idade; T24 - terra à vontade fornecida aos leitões a cada 24 horas do terceiro ao $19^{\circ}$ dia; T48 - terra à vontade fornecida aos leitões a cada 24 horas do terceiro ao $10^{\circ}$ dia e do $11^{\circ}$ ao $19^{\circ}$ dia, com intervalo de 48 horas; T72 - terra à vontade fornecida aos leitões a cada 24 horas do terceiro ao $10^{\circ}$ dia e do $11^{\circ}$ ao $19^{\circ}$ dia, com intervalo de 72 horas; SA suplemento alimentar ultraprecoce rico em ferro quelatado em pó (SAUP) fornecido do terceiro ao $11^{\circ}$ dia, com intervalo de 48 horas. $O$ ferro dextrano aplicado no terceiro dia de vida e a suplementação com terra e SAUP foram eficientes para garantir o desempenho de leitões no período de aleitamento e não influenciaram no consumo de ração nem na taxa de viabilidade. As diferentes fontes de ferro estudadas não influenciaram o leucograma e foram eficientes na prevenção da anemia ferropriva e no desempenho dos leitões lactentes. Com relação às concentrações de hemoglobina e hematócrito, os animais suplementados com ferro dextrano apresentaram valores superiores quando comparados aos que recebem terra e SAUP.
\end{abstract}

Palavras-chaves: suíno, ferro dextrano, parâmetros sanguíneos, terra

\begin{abstract}
In order to evaluate the use of different sources of iron to prevent iron deficiency anemia and to appraise the performance of suckling piglets, we sorted 202 piglets in five treatments. ID - intramuscular injection of 200mg of iron dextran on the third day of age; T24 - free daily access to land provided to piglets every 24 hours from the third to the nineteenth day; T48 - free daily access to land provided to piglets every 24 hours from the third to the tenth day and from day 11 to day 19 with an interval of 48 hours; T72 - free daily access to land provided to piglets every 24 hours from the third to the tenth day and from day 11 to day 19 with an interval of 72 hours; FS - Food supplement rich in iron-chelating powder (SAUP) available from the third to the eleventh day with an interval of 48 hours. The iron dextran applied on the third day of life as well as the supplementation with land and SAUP were effective to ensure the performance of piglets during the lactation period and did not affect feed intake or the viability rate. The different sources of iron studied did not influence the WBC (White Blood Cell) and succeded in preventing iron deficiency anemia and performance of suckling piglets. Regarding the concentrations of hemoglobin and hematocrit, the animals supplemented with iron dextran showed higher values when compared to those who receive land and SAUP.
\end{abstract}

Keywords: swine, iron dextran, blood parameters, land

Recebido em 11 de agosto de 2015

Aceito em 18 de fevereiro de 2016

E-mail: renzoasr@gmail.com 


\section{Almeida et al.}

\section{INTRODUÇÃO}

Os leitões nascem com uma reserva de aproximadamente $50 \mathrm{mg}$ de ferro e necessitam de $7 \mathrm{mg} /$ dia nas primeiras semanas de vida para seu crescimento. O leite da porca fornece cerca de $1 \mathrm{mg} /$ dia, o que pode ocasionar anemia ferropriva 10 a 14 dias após o nascimento do leitão. Isso ocorre devido à diminuição na biossíntese de hemoglobina caso alguma fonte extra de ferro não seja fornecida (Lopes, 1982; Svoboda e Drábek, 2003; Svoboda et al., 2004; Starzynski et al., 2013).

Segundo Oliveira e Barcellos (2012), a mortalidade decorrente da anemia ferropriva em criações confinadas quando não há suplementação de ferro pode chegar a $60 \%$. Nas últimas décadas, tem-se procurado determinar as concentrações e as formas ideais de suplementação de ferro para leitões lactentes, bem como melhorar sua utilização, por meio de estudos sobre apresentação de produtos e vias de administração. O método de eleição para a prevenção da anemia ferropriva tem sido a suplementação pela aplicação intramuscular ou subcutânea de compostos orgânicos de ferro (Bruininx et al., 2000; Vermeer et al., 2002; Wei, 2005; Starzynski et al., 2013).

Em leitões tratados com ferro via oral, a absorção é regulada em função das reservas do mineral e da atividade da eritropoetina. $\mathrm{O}$ ferro administrado oralmente é mais rapidamente disponível para a eritropoiese do que o ferro dextrano injetável. Isso provavelmente se deve ao fato de o ferro dextrano passar pelo sistema mononuclear fagocitário antes de estar disponível para incorporação à transferrina (Egeli e Framstad, 1999).

Neste sentindo, o acesso à terra com concentrações elevadas de ferro dispensa a aplicação de ferro dextrano (Szabo e Bikei, 2002). No entanto, o ferro torna-se insolúvel quando o $\mathrm{pH}$ é menor que três, a não ser que esteja ligado a um composto solúvel. Ingredientes da ração podem influenciar a solubilidade do ferro no lúmen intestinal. Alguns aminoácidos, como a glicina e a metionina, são capazes de aumentar sua absorção. $O$ ferro quelatado é uma possibilidade de suplementação oral em suínos, já que permanece intacto no trato gastrointestinal devido a sua alta estabilidade sendo absorvido como complexo aminoácido ou pequenos peptídeos (Yu et al., 2000, Hoffbrand et al., 2004). Segundo Svoboda e Drábek, (2003), o ferro quelatado como única fonte de ferro, na forma líquida, oferecido para leitões na fase de amamentação, não foi eficiente. No entanto, o acesso voluntário ao suplemento alimentar contendo ferro quelatado em pó com $110.000 \mathrm{mg} \cdot \mathrm{kg}^{-1}$ de ferro preveniu a anemia na maioria dos leitões e proporcionou ganho de peso semelhante ao de leitões tratados com ferro dextrano via intramuscular.

Por outro lado, tem sido sugerido que a aplicação parenteral de ferro pode elevar a ocorrência de doenças de origem bacteriana que causam diarreia e poliartrite. Tal fato pode ser devido à capacidade do ferro em lesar diferentes tecidos por catalisar a reação que converte peróxidos de oxigênio em íons radicais livres, destruindo membrana celular, proteínas e DNA (Szabo e Bikei, 2002; Grotto, 2010). É importante salientar também que não há via de excreção do ferro, mas ocorrem perdas pela pele, pelas mucosas e por sangramentos (Lorenzi et al., 2006).

Tanto o uso do ferro dextrano injetável quanto o da terra podem expor o animal a problemas sanitários. Entretanto, a terra colhida em área onde não há presença de animais apresenta menor risco de acarretar problemas sanitários. Adicionalmente, o contato com a terra pode representar estímulo à resposta imune do leitão. Apesar de, em granjas tecnificadas, o uso da terra não ser corrente, este manejo aproxima-se bastante das condições naturais de vida do suíno, o que torna este método uma alternativa de suplementação do ferro interessante, principalmente, para o pequeno produtor.

A despeito de o custo do ferro dextrano ser baixo, em média 21 centavos a dose, a aplicação via intramuscular pode representar uma dificuldade para o pequeno criador, já que este nem sempre possui conhecimentos necessários para armazenamento e aplicação adequada de produtos injetáveis, o que pode interferir na eficácia do produto. Assim, o oferecimento de terra representa uma opção de fácil manejo para as pequenas criações. 
Neste contexto, realizou-se o presente estudo com o objetivo de avaliar o uso de diferentes fontes de ferro na prevenção da anemia ferropriva e no desempenho de leitões lactentes.

\section{MATERIAL E MÉTODOS}

O experimento foi conduzido de acordo com os princípios éticos de pesquisa em animais, após aprovação pelo Comitê de Ética em Pesquisa Médica Humana e Animal do Hospital das Clínicas da Universidade Federal de Goiás, protocolo 123/05.

O estudo foi realizado em granja comercial na Fazenda Bonsucesso, localizada no município de Senador Canedo, estado de Goiás. Os leitões receberam ração peletizada comercial (Tab. 1), à vontade, a partir do $13^{\circ}$ dia de vida, e foram desmamados aos 19 dias de idade. Na granja onde o trabalho foi desenvolvido, os leitões já recebiam esse tipo de ração, portanto já estavam adaptados. Adicionalmente o desperdício desse tipo de ração é menor em relação à ração farelada.

Tabela 1. Composição da ração comercial utilizada na alimentação dos leitões a partir do $13^{\circ}$ dia de idade

\begin{tabular}{lc}
\hline Componentes da ração & $\begin{array}{c}\text { Valor } \\
\text { nutricional }\end{array}$ \\
\hline Umidade máxima (\%) & 12,5 \\
Proteína bruta mínima (\%) & 20 \\
Extrato etéreo mínimo (\%) & 4,5 \\
Material mineral máximo (\%) & 7,5 \\
Cálcio máximo (\%) & 1,1 \\
Fósforo mínimo (\%) & 0,65 \\
Lactose mínimo (\%) & 10 \\
Energia metabolizável (kcal) & $3.350,00$ \\
Ferro (mg $\mathrm{kg}^{-1}-$ conforme & 270 \\
analisado) & \\
\hline
\end{tabular}

Foram utilizadas 20 leitegadas (Landrace x Large White) híbridas (202 leitões), procedentes de porcas clinicamente saudáveis, de terceira ordem de parto. A uniformização de peso das leitegadas foi feita dentro de cada tratamento após o parto e a ingestão do colostro. Os leitões foram divididos em cinco tratamentos, sendo quatro leitegadas por tratamento: FD - ferro dextrano (Dexiron, Fatec, Brasil - com concentração de ferro de $100 \mathrm{mg} / \mathrm{mL}$ ) dose única de $200 \mathrm{mg}$, aplicada via intramuscular na região cervical, no terceiro dia de idade $(n=41)$; T24 - terra à vontade fornecida aos leitões a cada 24 horas do terceiro ao $19^{\circ}$ dia $(\mathrm{n}=40) ; \mathrm{T} 48$ - terra à vontade fornecida aos leitões a cada 24 horas do terceiro ao $10^{\circ}$ dia e do $11^{\circ}$ ao $19^{\circ}$ dia, com intervalo de 48 horas $(n=40)$; T72 - terra à vontade fornecida aos leitões a cada 24 horas do terceiro ao $10^{\circ}$ dia e do $11^{\circ}$ ao $19^{\circ}$ dia, com intervalo de 72 horas $(n=41)$ e SA suplemento alimentar ultraprecoce rico em ferro quelatado em pó - SAUP (Primofer, Tectron Saúde Animal, Brasil - com concentração de ferro $=132.000 \mathrm{mg} \cdot \mathrm{kg}^{-1}$ ) fornecido do terceiro ao $11^{\circ}$ dia, com intervalo de 48 horas $(n=40)$.

A terra foi fornecida à vontade, e o SAUP conforme as recomendações do fabricante, ambos em cochos colocados dentro das gaiolas de maternidade. A cada novo fornecimento, realizava-se a limpeza dos cochos. O consumo diário de terra não foi mensurado.

O delineamento experimental utilizado foi inteiramente ao acaso, com cinco tratamentos e quatro repetições. Para as variáveis de desempenho, a unidade experimental foi constituída de uma leitegada, enquanto para as variáveis incidência de diarreia, taxa de viabilidade, parâmetros sanguíneos e ferro no fígado e no baço, a unidade experimental foi constituída de um animal.

O desempenho dos leitões foi avaliado considerando-se as características zootécnicas de ganho de peso, consumo de ração e conversão alimentar. O consumo de ração foi medido pesando-se a quantidade de ração oferecida e diminuindo-se as sobras que eram pesadas no dia seguinte. Para as pesagens dos leitões e da ração, utilizou-se balança com sensibilidade de $5 \mathrm{~g}$ e capacidade máxima de $49.500 \mathrm{~g}$.

A conversão alimentar foi obtida pela relação CR:GP (consumo de ração dividido pelo ganho de peso). $\mathrm{Na}$ avaliação dos aspectos sanitários, considerou-se a ocorrência de diarreia, artrite e a taxa de viabilidade do terceiro ao $19^{\circ}$ dia de vida dos leitões, nos diferentes tratamentos, por meio de exame clínico individual, conforme recomendações de Plonait (1997).

Foram coletadas amostras de sangue, por punção da veia cava cranial ou cefálica (Moreno et al., 1997), de cinco leitões (um de cada tratamento) ao nascimento e de 20 leitões no dia do desmame (um de cada leitegada). De cada animal foram 
obtidos $10 \mathrm{~mL}$ de sangue, sendo $2 \mathrm{~mL}$ acondicionados em tubo de vidro com etilenodiaminotetracetato de sódio (EDTA) $1 \mathrm{mg} / \mathrm{mL}$, para realização do leucograma, do eritrograma e da contagem de reticulócitos (Rosenfeld, 1955), e $8 \mathrm{~mL}$ em tubos de ensaio para a obtenção do soro para quantificação de ferro sérico, ferritina sérica, capacidade total de ligação do ferro e índice de saturação da transferrina. As amostras foram encaminhadas ao Centro de Análises Clínicas Rômulo Rocha, da Faculdade de Farmácia/UFG, onde foram processadas imediatamente. Para obtenção das variáveis hematológicas, utilizou-se contador eletrônico, modelo ABX-pentra60 (Horiba-ABX Diagnostics, São Paulo, SP). Para dosagem de ferro sérico e capacidade total de ligação do ferro, foi utilizado o equipamento Bioplus-2000 (Bioplus, Brasil). Para ferritina e transferrina séricas, utilizou-se o equipamento Chiron Diagnostics Express-Plus (Chiron Diagnostics, Estados Unidos). Para a contagem de reticulócitos, utilizou-se a coloração de azul de cresil brilhante (Carvalho, 1999).

Para a determinação do ferro sérico, utilizou-se o reagente comercial Ferro crx ${ }^{\circledR}$ (Biotécnica Ltda., Brasil). O teste tubidimétrico foi utilizado para determinação quantitativa da ferritina (Turb FTN - Ferritina $^{\circledR}$, Ebram, Brasil). Para o estabelecimento da capacidade total de ligação do ferro (CTLF) e do índice de saturação da transferrina, utilizou-se reagente comercial de capacidade de ligação do ferro (Labtest Diagnóstica S.A., Brasil).
Após a coleta de sangue ao nascimento e ao desmame, os leitões foram submetidos à eutanásia por meio de traumatismo crânioencefálico, segundo resolução n.714, de 20/06/02, do Conselho Federal de Medicina Veterinária (Brasil, 2005), para a retirada do fígado e do baço para determinação dos teores de ferro. $\mathrm{O}$ material coletado foi estocado a $-20^{\circ} \mathrm{C}$. A concentração de ferro no ferro dextrano, na terra, no SAUP, na ração, no fígado e no baço foi determinada por meio da espectrofotometria de absorção atômica, usando-se o equipamento AA Analist 200 - Perkin Elmer (Yu et al., 2000). Essas análises foram realizadas no Centro de Pesquisa em Alimentos (CPA) da Escola de Veterinária e Zootecnia/UFG.

Os resultados foram analisados por ANOVA, com auxílio do sistema de análise estatística Sigma Stat32, sendo usados os teste de StudentNewman-Keuls e Kruskal-Wallis, com nível de significância de $5 \%$.

\section{RESULTADOS E DISCUSSÃO}

Os resultados relativos às características zootécnicas de peso, ganho de peso, consumo de ração e conversão alimentar, bem como a taxa de viabilidade, estão indicados na Tab. 2. Não foram observadas diferenças significativas $(\mathrm{P}>0.05)$, entre os diferentes tratamentos, quanto aos valores médios do peso dos leitões ao nascer. Aos 19 dias de idade, também não foram observadas diferenças significativas $(\mathrm{P}>0,05)$ nos valores obtidos de pesos médios, ganho de peso, consumo de ração, conversão alimentar e taxa de viabilidade nos diferentes tratamentos.

Tabela 2. Peso ao nascer, peso aos 19 dias, ganho de peso (GP), consumo de ração (CR), conversão alimentar (CA) e taxa de viabilidade (TV) dos leitões nos diferentes tratamentos aos 19 dias de idade

\begin{tabular}{ccccccc}
\hline Tratamentos & $\begin{array}{c}\text { Nascer } \\
(\mathrm{kg})\end{array}$ & $\begin{array}{c}19 \text { dias } \\
(\mathrm{kg})\end{array}$ & GP $(\mathrm{kg})$ & CR $(\mathrm{g})$ & CA & TV $(\%)$ \\
\hline FD & 1,39 & 5,17 & 3,79 & 209,52 & 0,056 & 92,73 \\
T24 & 1,44 & 5,47 & 4,04 & 133,75 & 0,033 & 100,00 \\
T48 & 1,49 & 5,71 & 4,22 & 169,50 & 0,041 & 97,92 \\
T72 & 1,33 & 4,97 & 3,63 & 132,07 & 0,033 & 95,45 \\
SA & 1,52 & 5,82 & 4,30 & 113,75 & 0,029 & 100,00 \\
Significância & 0,85 & 0,52 & 0,48 & 0,61 & 0,45 & 0,35 \\
(P) & 16,33 & 11,15 & 12,00 & 55,5 & 55,9 & 11,55 \\
CV(\%) & & & & & \\
\hline
\end{tabular}

Teste de Kruskal-Wallis. 
No desempenho de leitões aos 21 dias, Nunes (1980), Lopes (1982), Santana (1982), Svoboda e Drabek (2003) encontraram resultados semelhantes com ferro dextrano injetável e terra, confirmando a eficiência da suplementação de ferro via terra no desempenho de leitões. Yu et al. (2000) e Svoboda e Drabek (2003), ao estudarem a biodisponibilidade do complexo ferro aminoácido quelatado, também encontraram resultados semelhantes em relação ao ganho de peso e à conversão alimentar. Monteiro (2006), ao comparar a suplementação de leitões com ferro dextrano e suplemento alimentar ultraprecoce rico em ferro quelatado em pó (SAUP), também não observou diferenças entre os pesos médios dos animais.

Por outro lado, Nunes (1980), em leitões com 40 dias de idade, forneceu terra $\left(37 \mathrm{mg} \cdot \mathrm{kg}^{-1}\right)$, ferro dextrano injetável $(100 \mathrm{mg})$ e ferro aminoácido quelatado (850mg) a porcas gestantes e lactentes via ração e verificou a superioridade de desempenho dos leitões suplementados com ferro dextrano em detrimento dos leitões suplementados com terra e dos leitões suplementados via leite. No presente trabalho, o bom desempenho dos leitões dos grupos T24, $\mathrm{T} 48$, T72, e SA, provavelmente, foi relacionado à alta concentração de ferro na terra e no SAUP.

Considerando-se os resultados do hemograma, não foram observadas diferenças $(\mathrm{P}>0,05)$ nos valores do leucograma para os animais nos diferentes tratamentos. No eritrograma, verificou-se que os leitões suplementados com ferro dextrano apresentaram valores superiores de hemoglobina e hematócrito $(\mathrm{P}<0,05)$ quando comparados aos que receberam terra e SAUP (Tab. 3).

Tabela 3. Eritrograma de leitões recebendo diferentes fontes de ferro

\begin{tabular}{cccccccc}
\hline Tratamento & $\begin{array}{c}\text { HEM } \\
\left(10^{12} / \mathrm{l}\right)\end{array}$ & $\begin{array}{c}\text { HB } \\
(\mathrm{g} / \mathrm{Dl})\end{array}$ & $\begin{array}{c}\text { HT } \\
(\%)\end{array}$ & $\begin{array}{c}\text { VGM } \\
(\mathrm{fl})\end{array}$ & $\begin{array}{c}\text { HGM } \\
(\mathrm{pg})\end{array}$ & $\begin{array}{c}\text { CHGM } \\
(\mathrm{g} / \mathrm{dL})\end{array}$ & $\begin{array}{c}\text { RDW } \\
(\%)\end{array}$ \\
\hline Valores de & $4,40-$ & $9,00-$ & $35,50-$ & $70,00-$ & $19,00-$ & $26,00-$ & \\
referência* & 5,30 & 11,20 & 40,50 & 82,00 & 23,00 & 29,00 & \\
Ao nascer & 5,63 & 12,14 & 39,66 & 70,75 & 21,56 & 30,52 & 17,90 \\
FD & 6,54 & $13,63 \mathrm{a}$ & $44,38 \mathrm{a}$ & $68,26 \mathrm{a}$ & $20,96 \mathrm{a}$ & 30,71 & 18,78 \\
T24 & 5,75 & $11,40 \mathrm{~b}$ & $37,15 \mathrm{~b}$ & $64,80 \mathrm{ac}$ & $19,94 \mathrm{ab}$ & 30,74 & 20,28 \\
T48 & 6,11 & $10,03 \mathrm{~b}$ & $33,05 \mathrm{~b}$ & $54,02 \mathrm{~b}$ & $16,41 \mathrm{~b}$ & 30,37 & 20,93 \\
T72 & 5,65 & $10,50 \mathrm{~b}$ & $34,20 \mathrm{~b}$ & $60,44 \mathrm{ab}$ & $18,55 \mathrm{ab}$ & 30,66 & 21,63 \\
SA & 5,99 & $10,25 \mathrm{~b}$ & $33,20 \mathrm{~b}$ & $55,61 \mathrm{bc}$ & $17,20 \mathrm{ab}$ & 30,92 & 23,95 \\
\hline Significância (P) & 0,38 & 0,01 & 0,01 & 0,02 & 0,03 & 0,87 & 0,07 \\
CV(\%) & 10,40 & 11,86 & 12,5 & 9,41 & 10,23 & 2,26 & 10,03 \\
\hline
\end{tabular}

$\mathrm{HEM}=$ contagem de hemácias; $\mathrm{HB}=$ dosagem de hemoglobina; HT=hematócrito; VGM=volume globular médio; HGM=hemoglobina globular média; CHGM=concentração de hemoglobina globular média; RDW="Red Cell Distribution Width"; fl= fentolitro; pc=picogramas; g= grama; $\mathrm{L}=$ litro. Médias com letras distintas nas colunas indicam diferenças estatisticamente significativas.

Teste de Student-Newman-Keuls. * Jain (1993) leitões com 20 dias de idade.

Os valores da contagem global de leucócitos, da contagem diferencial de bastonetes, de neutrófilos segmentados, de monócitos, da contagem de hemácias e da dosagem da concentração de hemoglobina dos leitões ao nascimento foram superiores aos valores de referência para os leitões aos 20 dias de idade (Tab. 3). A idade apresenta-se como uma variação fisiológica sobre o leucograma em humanos e suínos (Jain, 1993, Lewis et al., 2006), o que também foi observado neste trabalho.
A ausência de alterações no leucograma ocorrida neste estudo também foi relatada por Santana (1982) e Egeli e Framstad (1999), ao avaliarem o efeito da aplicação intramuscular de ferro dextrano em leitões no primeiro, terceiro e quarto dias após o nascimento. No entanto, Svoboda et al. (2004), ao trabalharem com leitões deficientes em ferro, verificaram diminuição na circulação de linfócitos $\mathrm{B}$ e concluíram que a deficiência de ferro influenciou na imunocompetência dos leitões. No presente estudo, este tipo de relação 
não pode ser avaliada, uma vez que não foi realizada a tipificação dos linfócitos.

A suplementação de ferro com ferro dextrano, terra e SAUP foi adequada do ponto de vista clínico, visto que os leitões não apresentaram anemia. Os valores superiores de hemoglobina e hematócrito nos leitões suplementados com ferro dextrano também foram relatados por Lopes (1982), ao comparar a suplementação com terra e ferro dextrano, e por Svoboda e Drabek (2003), ao avaliarem a eficiência do suplemento com ferro quelatado e ferro dextrano. Por outro lado, Monteiro (2006) observou, para o grupo de leitões suplementados com SAUP, aumento significativo nas concentrações de hemoglobina $(12,19 \mathrm{~g} / \mathrm{dL})$ no sangue, em comparação à suplementação com ferro dextrano $(11,75 \mathrm{~g} / \mathrm{dL})$. Esta diferença não pode ser atribuída ao tipo de SAUP, pois, nos dois estudos, foi utilizado o mesmo produto comercial.

Nunes et al. (1997), ao compararem a aplicação de ferro dextrano (200mg) e o acesso controlado e livre à terra, demonstraram que, na prevenção da anemia ferropriva, as suplementações de ferro por intermédio do acesso à terra diariamente e de ferro dextrano foram eficientes (hemoglobina igual a $11,28 \mathrm{~g} / \mathrm{dL}$ e $11,19 \mathrm{~g} / \mathrm{dL}$, respectivamente). No entanto, ao se oferecer terra com intervalo de um e dois dias, ocorreram valores mais baixos de hemoglobina $(9,88 \mathrm{~g} / \mathrm{dl}$ e $9,96 \mathrm{~g} / \mathrm{dl}$, respectivamente). Neste estudo, não houve diferença nos parâmetros do eritrograma quanto se modificou a frequência de oferecimento da suplementação com a terra, após o $10^{\circ}$ dia, evidenciando a importância da suplementação diária de ferro nos primeiros dias após o nascimento.

Szabo e Bikei (2002), na Hungria, ao estudarem 4.691 leitões criados ao ar livre, verificaram que, aos 34 dias após o nascimento, os animais não suplementados com ferro dextrano apresentaram valor médio de hemoglobina de $5,1 \mathrm{~g} / \mathrm{dL}$, e os suplementados $10,1 \mathrm{~g} / \mathrm{dL}$. Os leitões suplementados com ferro dextrano apresentaram melhor desempenho, menor taxa de viabilidade e índices adequados de hemoglobina.

Ainda quanto à taxa de viabilidade, nos grupos T24 e SA, não foi registrado nenhum óbito. Maiores taxas de mortalidade em grupos de leitões aos 21 dias suplementados com ferro dextrano também foram apontados por Nunes (1980) e Lopes (1982), em comparação aos suplementados com terra. Monteiro (2006) relatou que leitões recebendo ferro dextrano apresentaram elevação $(\mathrm{P}<0,05)$ na incidência de mortalidades e de diarreias, quando comparados aos que receberam SAUP. A baixa taxa de viabilidade e a maior ocorrência de problemas sanitários registrada nos animais suplementados com ferro dextrano, possivelmente, devem-se ao fato de que a aplicação parenteral pode interferir no mecanismo de regulação e o mineral ficar disponível em excesso, o que poderia resultar em diminuição da taxa de viabilidade de leitões (Szabo e Bikei, 2002). Recentemente, foi demonstrado que o excesso de ferro dextrano em leitões induz a expressão excessiva de hepcidina no fígado, que, por sua vez, pode prejudicar tanto a utilização de suplemento de ferro depositado no sistema reticulo endotelial nos macrófagos quanto a absorção do ferro dietético (Starzynski et al., 2013).

Não se observou diarreia ou artrite nos animais nos diferentes tratamentos, o que indicou ausência desse efeito adverso no grupo que recebeu ferro dextrano, apesar de existirem evidências de que a administração parenteral de ferro pode causar aumento da morbidade em leitões, diarreia, bacteremia e poliartrite (Szabo e Bikei, 2002; Decuadro, 2006).

Com relação ao ferro sérico e ao IST, foi verificado que os animais suplementados com o SAUP (SA) apresentaram valores inferiores $(\mathrm{P}<0,05)$ quando comparados com os de outros tratamentos, no entanto não foram observadas diferenças na quantificação de ferritina e CTLF (Tab. 4). Neste trabalho, as concentrações de ferro das diferentes fontes disponibilizadas foram suficientes para manter os estoques de ferro no organismo animal. Estes resultados diferem de Calvo e Allue (1986) que, ao estudarem o metabolismo do ferro, quantificando ferro sérico e ferritina sérica, em leitões do nascimento aos 50 dias de idade suplementados com 100mg de ferro dextrano administrado no quarto dia após o nascimento, verificaram que a suplementação não foi suficiente para evitar o aparecimento de anemia ferropriva e também não foi suficiente para manter as reservas desse metal durante $o$ período de amamentação. 
Tabela 4. Resultados da avaliação da contagem de reticulócitos (RET), da contagem de plaquetas (PLAQ), do ferro sérico (FE) e da ferritina sérica (FT), da capacidade total de ligação do ferro (CTLF), do índice de saturação de transferrina (IST) e da concentração de ferro no fígado e no baço de leitões recebendo diferentes fontes de ferro

\begin{tabular}{|c|c|c|c|c|c|c|c|c|}
\hline Tratamento & $\begin{array}{c}\text { RET* }^{*} \\
\%\end{array}$ & $\begin{array}{l}\text { PLAQ* } \\
10^{3} / \mu \mathrm{L}\end{array}$ & $\begin{array}{c}\mathrm{FE}^{*} \\
\mu \mathrm{g} / \mathrm{dLl}\end{array}$ & $\begin{array}{c}\mathrm{FT}^{*} \\
\mathrm{ng} / \mathrm{mL}\end{array}$ & $\begin{array}{l}\text { CTLF* } \\
\mu \mathrm{g} / \mathrm{dL}\end{array}$ & $\begin{array}{c}\text { IST* }^{*} \\
\%\end{array}$ & $\begin{array}{c}\text { FÍGADO } \\
* * \\
\mathrm{mg} \cdot \mathrm{kg}^{-1}\end{array}$ & $\begin{array}{c}\text { BAÇO* } \\
* \\
\text { mg.kg }{ }^{-1}\end{array}$ \\
\hline $\begin{array}{c}\text { Valor de } \\
\text { referência*** }\end{array}$ & $\begin{array}{l}5,7- \\
17,1\end{array}$ & $200-845$ & $\begin{array}{l}17- \\
212\end{array}$ & - & - & - & - & - \\
\hline AO NASCER & 5,14 & 240,80 & 77,58 & 182,90 & 370,50 & 33,48 & 58,50 & 60,00 \\
\hline FD & 6,50 & 730,00 & $178,65^{\mathrm{a}}$ & $367,68^{\mathrm{a}}$ & 650,22 & $40,11^{\mathrm{a}}$ & 76,25 & 46,25 \\
\hline $\mathrm{T} 24$ & 6,00 & 729,25 & $151,88^{\mathrm{a}}$ & $204,58^{b}$ & 736,91 & $28,89^{\mathrm{ab}}$ & 15,50 & 25,50 \\
\hline $\mathrm{T} 48$ & 9,75 & 700,00 & $178,65^{\mathrm{a}}$ & $251,15^{\mathrm{a}}$ & 780,58 & $29,98^{\mathrm{ab}}$ & 8,75 & 36,75 \\
\hline $\mathrm{T} 72$ & 7,75 & 746,50 & $119,93^{\mathrm{a}}$ & $\underset{\mathrm{b}}{246,15^{\mathrm{a}}}$ & 779,80 & $18,34^{\mathrm{b}}$ & 10,00 & 28,00 \\
\hline SA & 5,50 & 819,75 & $74,93^{\mathrm{b}}$ & $\underset{\mathrm{b}}{246,60^{\mathrm{a}}}$ & 742,04 & $11,27^{\mathrm{b}}$ & 9,00 & 24,50 \\
\hline $\begin{array}{l}\text { Significância } \\
\text { (P) }\end{array}$ & 0,08 & 0,86 & $<0,001$ & 0,04 & 0,56 & 0,01 & 0,33 & 0,19 \\
\hline CV $(\%)$ & 26,3 & 34,16 & 17,38 & 26,47 & 13,88 & 28,35 & - & 37,28 \\
\hline
\end{tabular}

$\mathrm{VR}=$ valor de referência. Médias com letras distintas nas colunas indicam diferenças estatisticamente significativas. *Teste de Student-Newman-Keuls. **Teste de Kruskal-Wallis.

****Moreno et al. (1997) para leitões desmamados.

Não foram observadas diferenças $(\mathrm{P}>0,05)$ nos valores obtidos na concentração do ferro no fígado e no baço dos animais nos diferentes tratamentos. Apesar de este estudo não evidenciar diferenças nas concentrações de ferro no fígado e no baço frente aos diferentes suplementos, Yu et al. (2000), ao determinarem a concentração de ferro nesses órgãos, verificaram melhor biodisponibilidade do complexo aminoácido quelatado, com $60.000 \mathrm{mg} \cdot \mathrm{kg}^{-1} \mathrm{de}$ ferro, comparado à suplementação com sulfato ferroso.

Neste trabalho, a coloração da terra utilizada foi vermelha e o exame químico evidenciou uma concentração de ferro de $61.000 \mathrm{mg} \cdot \mathrm{kg}^{-1}(6,1 \%)$. Segundo Ladeira et al. (2002), o solo de coloração vermelha distingue-se dos demais, principalmente pelo elevado teor de óxidos de ferro $10,6 \%$. Foi verificado ainda que o teor de óxidos dos solos tanto de coloração marrom quanto de amarela é bem inferior, tendo sido registrados $5,0 \%$ e $4,4 \%$, respectivamente. Considerando-se a coloração e a composição das terras de diferentes colorações, sugere-se classificar as terras de coloração vermelha como terras ricas em ferro e as demais como terras pobres em ferro. Com base no exame químico e na coloração, pode-se afirmar que, no presente trabalho, foi utilizada terra rica em ferro.

A avaliação do tipo de terra realizada neste estudo é relevante, uma vez que alguns trabalhos têm demonstrado que terras com diferentes concentrações de ferro foram eficientes na prevenção da anemia em leitões. No Brasil, Nunes (1980) trabalhou com terra com $370 \mathrm{mg} \cdot \mathrm{kg}^{-1}$, Lopes (1982) com terra com 3,11 e $18 \mathrm{mg} \cdot \mathrm{kg}^{-1}$, Santana (1982) com 370mg. $\mathrm{kg}^{-1} \mathrm{e}$ Nunes (1997) com terra com $17,7 \mathrm{mg} \cdot \mathrm{kg}^{-1}$. Na Escócia, Brown et al. (1996) encontraram na terra teores de ferro de 4.100 a $30.800 \mathrm{mg} . \mathrm{kg}^{-1} \mathrm{em}$ diferentes propriedades.

Considerando-se o que está descrito na literatura e o que foi observado neste estudo, pode-se sugerir que a disponibilidade do ferro na terra para leitões lactentes não depende exclusivamente da concentração de ferro na terra, mas também da presença de outros nutrientes. Neste contexto, o T4 pode ser uma opção técnica e econômica recomendável, pois a taxa de viabilidade foi de $100 \%$ e não houve diferença no ganho de peso em relação aos outros tratamentos, além de a suplementação de ferro ser eficiente na prevenção da anemia- 


\section{CONCLUSÕES}

O ferro dextrano, a terra e o suplemento alimentar ultraprecoce rico em ferro quelatado (SAUP) em pó são eficientes para garantir adequado desempenho de leitões no período de aleitamento e não influenciaram o consumo de ração e a taxa de viabilidade. As diferentes fontes de ferro estudadas não influenciaram nos valores do leucograma e foram eficientes na prevenção da anemia ferropriva em leitões. A concentração da hemoglobina e o hematócrito em animais suplementados com ferro dextrano apresentaram valores superiores quando comparados aos que receberam terra e suplemento alimentar ultraprecoce rico em ferro quelatado em pó.

\section{REFERÊNCIAS}

BRASIL. Conselho Federal de Medicina Veterinária. Resolução n.714 de 20 de junho de 2002. Dispõe sobre procedimentos e métodos de eutanásia em animais, e dá outras providências. Diário Oficial da União. Brasília, 21 de junho de 2002. Seção 1, p.201.

BROWN, J.M.C.; EDWARDS, S.A.; SMITH, W.J. et al. Welfare and production implications of teeth clipping and iron injection of piglets in outdoor systems in Scotland. Prev. Vet. Med., v.27, p.95-105, 1996.

BRUININX, E.M.A.M.; SWINKELS, J.W.G.M.; PARMENTIER, H.K. et. al. Effects of an additional iron injection on growth and humoral immunity of weanling pigs. Livest. Prod. Sci., v.67, p.31-39, 2000.

CALVO. J.J.; ALLUE, J.R. Plasma ferritin and other parameters related to iron metabolism in piglets. Comp. Biochem. Physiol. A, v.85, p.471479, 1986.

CARVALHO, W.F. Técnicas médicas de hematologia e imuno-hematologia. 7.ed. Belo Horizonte: Coopemed, 1999. 180p.

DECUADRO, H. Abordagem prática da síndrome diarreica na maternidade. In: CONGRESSO LATINO-AMERICANO DE SUINOCULTURA, 3., 2006, Foz do Iguaçu. Anais... Foz do Iguaçu: [AnimalWorld], 2006. p.167-178.
EGELI, A.K.; FRAMSTAD, T. An evaluation of iron-dextran supplementation in piglets administered by injection on the first, third or fourth day after birth. Res. Vet. Sci., v.66, p.179184, 1999.

GROTTO, H.Z.W. Fisiologia e metabolismo do ferro. Rev. Bras. Hematol. Hemoter, v.32, p.817,2010

HOFFBRAND, A.V.; PETTIT, J.E.; MOSS, P.A.H. Fundamentos em hematologia. 4.ed. São Paulo: Artmed, 2004. 358p.

JAIN, N.C. Blood loss or hemorrhagic anemias. In: $\quad$ (Ed.). Essentials of veterinary hematology. 4.ed. Philadelphia: Lea \& Febiger, 1993. p.28-29.

LADEIRA, A.C.Q.; CIMINELLI, V.S.T.; NEPOMUCENO, A.L. Seleção de solos para a imobilização de arsênio. Rev. Esc. Minas, v.55, p.215-221, 2002.

LEWIS, S.M.; BAIN, B.J.; BATES, I. Hematologia prática de Dacie e Lewis. 9.ed. Porto Alegre: Artmed, 2006. 572p.

LOPES, E.L. Efeito do emprego de terra com diferentes níveis de ferro sobre o desempenho e prevenção de anemia de leitões. 1982. 30f. Dissertação (Mestrado em Medicina Veterinária) - Escola de Veterinária, Universidade Federal de Minas Gerais, Belo Horizonte, MG.

LORENZI, F.T.; D'AMICO, E.; DANIEL, M.M. et al. Manual de hematologia propedêtica $e$ clínica. 3.ed. Rio de Janeiro: Medsi, 2006. 665p.

MONTEIRO, D.P. Utilização de um suplemento alimentar a base de ferro quelatado em substituição ao ferro dextrano na fase pré inicial de vida dos leitões. 2006. 50f. Dissertação (Mestrado em Ciências Veterinárias) - Setor de Ciências Agrárias, Universidade Federal do Paraná, Curitiba, PR.

MORENO, A.M.; SOBESTIANSKY, J.; LOPES, A.C. et al. Colheita e processamento de amostras de sangue em suínos para fins de diagnóstico. Concórdia: EMBRAPA CNPSA, 1997. 30p.

NUNES, R.C. Efeito de várias fontes de ferro no desempenho de leitões aos 21 e 40 dias de idade. 1980. 40f. Dissertação (Mestrado em Medicina Veterinária) - Escola de Veterinária, Universidade Federal de Minas Gerais, Belo Horizonte, MG. 
NUNES, R.C.; BANDEIRA, M.N.; THOMÉ, W.U. et al. Uso de ferro dextrano e acesso controlado e livre à terra no desempenho e prevenção da anemia ferropriva dos leitões. Anais Esc. Agron. Vet., v.27, p.49-55, 1997.

OLIVEIRA, S.J; BARCELLOS, D. Anemia ferropriva. In: SOBESTIANSKY, J. BARCELlOS, D. (Eds.). Doenças dos suínos. 2.ed. Goiânia: Cânone editorial, 2012. p.719722.

PLONAIT, H. Der tierarzt im bestand, klinische untersuchung und probenentnahme. In: PLONAIT, H. BICKHARDT, K. Lehrbuch der schweinekranheiten. 2.ed. Berlin: Paul Parey, 1997. $7 \mathrm{p}$.

ROSENFELD, G. Etilenodiamina tetracética dissódica (EDTA) como anticoagulante para técnica hematológica. Rev. Clín. São Paulo, v.31, p.65-71, 1955.

SANTANA, A.E. Estudo do quadro hemático de leitões alimentados com diferentes fontes de ferro. 1982. 41f. Dissertação (Mestrado em Medicina Veterinária) - Escola de Veterinária, Universidade Federal de Minas Gerais, Belo Horizonte, MG.

STARZYŃSKI, R.R.; LAARAKKERS, C.M.; TJALSMA, H. et al. Iron supplementation in suckling piglets: how to correct iron deficiency anemia without affecting plasma hepcidin levels. Plos One. v.8, p.e64022, 2013.
SVOBODA, M., DRÁBEK, J. Efficiency of voluntary consumption of amino acid-chelated iron in preventing anaemia of suckling piglets. Acta Vet. Brno, v.72, p.499-507, 2003.

SVOBODA, M.; DRABEK, J.; KREJCI, J. et al. Impairment of the peripheral lymphoid compartment in iron-deficient piglets. J. Vet. Med., v.51, p.231-237, 2004.

SZABO, P.; BIKEI, G. Iron deficiency in outdoor pig production. J. Vet. Med. Ser. A. Physiol. Pathol. Clin. Med., v.49, p.390-391, 2002.

VERMEER, J.E.; KUIJPERS, A.H.; ELBERS, A.R. Comparison of the efficacy of two different iron supplements for anemia prevention in piglets. Tijdschr. Diergeneeskd., v.127, p.110114, 2002.

WEI, K.Q.; XU, Z.R.; LUO, X.G. et al. Effects of iron from an amio acid complexo on the iron status of neonatal and suckling piglets. AsianAustralas. J. Anim. Sci., v.18, p.1485-1491, 2005.

YU, B.; HUANG, W.; CHIOY, P.W. Bioavailability of iron from amino acid in weanling pigs. Anim. Feed Sci. Technol., v.86, p.39-52, 2000. 